\title{
Thermal curing of mesophase pitch: An alternative to oxidative stabilisation for the development of carbon-carbon composites
}

\author{
A. Centeno, R. Santamaría, M. Granda, R. Menéndez, *C. Blanco \\ Instituto Nacional del Carbón, CSIC, Apdo. 73, 33080-Oviedo, Spain
}

\begin{abstract}
Thermal curing of mesophase pitch was studied as an alternative to oxidative stabilisation for the development of carbon-carbon composites, with the aim of avoiding several problems associated to the oxidative process such as thickness limitations or gradients in the properties of the resultant materials. Carbon fibre preforms densified with the mesophase were submitted to thermal treatments at temperatures between 400 and $475^{\circ} \mathrm{C}$ for different periods in order to promote polymerisation and thus avoid exudation of the matrix precursor during carbonisation. Changes induced in the matrix precursor were monitored by thermogravimetric analysis and infrared spectroscopy. The effectiveness of the treatments was evaluated from the porosity of the resultant materials after carbonisation. The highest degree of polymerisation of the matrix precursor was achieved with treatments at $400^{\circ} \mathrm{C}$ for $24 \mathrm{~h}$ or $475^{\circ} \mathrm{C}$ for $5 \mathrm{~h}$, the resultant materials having similar porosity values to those obtained by oxidative stabilisation.
\end{abstract}

Keywords.- Carbon-carbon composites; mesophase; thermal curing; oxidative stabilization

*Clara Blanco: corresponding author; clara@incar.csic.es; Fax.: +34 985297662 


\section{1.- Introduction}

Carbon fibre reinforced carbon matrix (CC) composites are an important group of materials that can have high specific strength and stiffness at elevated temperatures, high thermal conductivity and excellent dimensional stability. They are widely used in high performance applications in the military industry and, in considerable quantities, as friction elements in aircraft braking systems $[1,2]$. They have also attracted attention as candidate materials for thermal management in several new applications such as heat sinks, substrates for electronic elements and plasma facing components of fusion devices [3-5]. CC composites with an extremely high thermal conductivity are required for these applications.

In the conventional fabrication of CC composites, the matrices are either derived from polymer resin or pitch precursors, or from gaseous hydrocarbons [2]. From these precursors, pitches are attractive due to their high carbon yield and high degree of graphitizability in comparison with resins, and low processing costs in comparison to chemical vapour infiltration necessary to obtain matrices from hydrocarbons $[6,7]$. In particular, the use of mesophase pitch instead of conventional pitches have several advantages, especially for the development of high thermal conductivity materials, as mesophase has significantly higher carbon yield (up to 75-80 wt. \%) and higher degree of graphitizability $[8,9]$. Nonetheless, the impregnation processes involving mesophase pitches might be more difficult, due to their higher viscosity and the higher operating temperatures required [10]. 
The fabrication of CC composites using mesophase pitch as matrix precursor usually includes an intermediate stage of oxidative stabilisation to avoid swelling during carbonisation and thus reducing the porosity of the final material. This is a similar process to that widely used in the preparation of carbon fibres [11, 12] and has also been reported to optimize the sintering ability of mesophase to produce polygranular graphites [13]. Oxidative stabilisation depends on the transport of oxygen into a reactive medium where oxidation reactions introduce various oxygen functionalities on the complex molecules of the mesophase, promoting their polymerisation/condensation and thus reducing the plasticity of the precursor $[14,15]$. Although reaction rates become significant at high temperatures $\left(>200-300^{\circ} \mathrm{C}\right)$, diffusion of oxygen into the reactive medium is better at lower temperatures. In fact, incomplete stabilisation regions were observed in the core of carbon filaments resulting in the formation of skin-core microstructures after carbonization and oxygen gradients [16]. This becomes a critical issue when stabilising mesophase matrices in CC composites, as oxygen needs to diffuse through a significantly thicker sample. Several studies confirmed the higher effectiveness of lower oxidation temperatures (as low as $150^{\circ} \mathrm{C}$ ) to stabilise mesophase in depth [17-19]. However, reactions at such low temperatures are rather slow, which makes the processing extremely long. Farthollahi et al. [20] found that the combination of low temperatures and moderate oxygen pressures raised the oxygen uptake increasing the stabilization depths. Dumont et al. [21] studied the addition of quinones to mesophase pitch in order to suppress the swelling during carbonisation. However, the reactions promoted by the quinones caused a reduction of the anisotropy of the final material, one of the advantages of using mesophase pitch as carbon precursor. 
In this study, thermal curing of mesophase pitch is proposed as an alternative to oxidative stabilisation for the development of CC composites. Similar to the curing process applied to resins, once densified with the mesophase pitch, the composite is submitted to a thermal treatment at temperatures around $400^{\circ} \mathrm{C}$ in order to promote mesophase polymerisation and thus reduce exudation from the carbon fibre preform during carbonisation. Several conditions are studied and the results obtained compared with those obtained by oxidative stabilisation.

\section{2.- Experimental}

2.1.- Densification of carbon fibre preforms.

Naphthalene derived mesophase pitch (AR) supplied by Mitsubishi Gas Chemical was used as matrix precursor to densify 2D PAN-based carbon fibre preforms supplied by SGL Carbon Group. Carbon-carbon composites were obtained by liquid impregnation of the carbon fibre preforms with the mesophase pitch. The preform was introduced in an autoclave and covered with the matrix precursor. The autoclave was heated under vacuum up to $350^{\circ} \mathrm{C}$, temperature that ensures the melting of the precursor. Then, a nitrogen pressure of $0.5 \mathrm{MPa}$ was applied in order to force the precursor into the

preform. After three hours at these conditions it was left to cool down to room temperature under pressure.

\subsection{Thermal curing of densified preforms.}

The densified preforms were submitted to thermal curing prior to carbonisation, in order reduce the fluidity of the mesophase matrix precursor and therefore avoid its exudation from the preform. Thermal curing consisted on a thermal treatment under nitrogen to 
promote the polymerisation of mesophase components. The effect of different parameters (such as temperature, pressure and time) was studied in order to select the best conditions.

\subsection{Oxidative stabilisation of densified preforms.}

The densified preforms were submitted to a conventional oxidative stabilisation process prior to carbonisation in order to compare the resultant materials with those obtained by thermal curing. Stabilisation was carried out at $170^{\circ} \mathrm{C}$ for $24 \mathrm{~h}$ followed by $12 \mathrm{~h}$ at $200^{\circ} \mathrm{C}$, under air (20 L/min). These conditions had been previously optimised.

\subsection{Carbonisation of carbon-carbon composites}

After the intermediate stage of either thermal curing or oxidative stabilisation, composites were submitted to carbonisation at $1000^{\circ} \mathrm{C}$ to obtain the final carbon-carbon composite materials. Carbonisation was carried out in a horizontal furnace using a heating rate of $1^{\circ} \mathrm{C} / \mathrm{min}$ and a nitrogen flow of $65 \mathrm{~mL} / \mathrm{min}$. The final temperature was maintained for 30 min after which the sample was left to cool down to room temperature.

\subsection{Monitoring of the thermal curing process.}

The thermal curing process was studied from the loss of matrix precursor during the treatment and after final carbonisation. As the carbon fibres of the preform had been already treated to higher temperatures during their processing $\left(>1000^{\circ} \mathrm{C}\right)$, it is reasonable to assign all the mass changes to the loss of matrix, either by exudation or by loss of mass associated to the pyrolysis processes. The effectiveness of the treatment 
was studied from the loss of matrix during carbonization (referred to the matrix remaining in the preform after curing) and the total matrix lost during the whole process (referred to the matrix content in the densified preform).

Changes induced in the matrix precursor by the thermal curing process were also evaluated by thermogravimetric analysis of the precursor remaining after each treatment. TG (mass loss) and DTG (first derivative of mass loss with respect to time) curves were obtained in a TA Instruments SDT 2960 thermal analyser on $10 \mathrm{mg}$ of sample. The temperature was increased up to $1000^{\circ} \mathrm{C}$ at a heating rate of $10^{\circ} \mathrm{C} \mathrm{min}{ }^{-1}$ under a nitrogen flow of $95 \mathrm{~mL} \mathrm{~min}^{-1}$. The results obtained were compared to those corresponding to the parent mesophase pitch (AR).

Infrared spectroscopy was also used to monitor the changes induced in the precursor by the thermal curing process. Fourier transformed infrared (FTIR) spectra were obtained by diffuse reflectance, using a Nicolet 8700 spectrometer equipped with a DTGS TEC detector, operating at a sub-ambient temperature. Powdered samples $(<100 \mu \mathrm{m})$ were loaded into a DRIFT microcup and the surface was levelled. The spectra were recorded from 500 to $4000 \mathrm{~cm}^{-1}$ by averaging 128 scans at a resolution of $4 \mathrm{~cm}^{-1}$. The spectra were converted to the Kubelka-Munk function. The aromaticity index of the samples was semi-quantitatively determined as the ratio between the areas corresponding to the aromatic C-H stretching band (3150-2990 $\mathrm{cm}^{-1}$ ) and both aromatic (3150-2990 $\mathrm{cm}^{-1}$ ) and aliphatic (2990-2800 $\left.\mathrm{cm}^{-1}\right) \mathrm{C}-\mathrm{H}$ stretching bands, using the formula $\mathrm{IAr}=\mathrm{A} 3150-$ 2990/(A3150-2990 +A2990-2800) [22]. 


\section{3.- Results and discussion}

The initial porosity of the carbon fibre preform was reduced from 40 vol. $\%$ to 7 vol. \% after densification with the mesophase pitch. However, when the composite is carbonized to $1000^{\circ} \mathrm{C}$ the porosity raises to $27 \%$ (Table 1 ). This is caused by the fluidity of the matrix precursor that exudes from the preform and also by the weight loss associated with the pyrolysis of the mesophase. The overall mass of matrix lost in the carbonization process is $59 \%$. Considering that the carbon yield of the mesophase pitch is around 80 wt. \% (see Figure 1a), around 39 wt. \% of precursor is lost due to exudation. This evidences the necessity for a treatment prior to carbonization that reduces the fluidity of the pitch. As explained before, oxidative stabilization is generally used for this purpose. In the best stabilisation conditions found for this sample (described in the experimental section), the final porosity of the resultant material is 22 vol. \%.

The conditions for the thermal treatment were selected taking into account the pyrolysis behaviour of the matrix precursor AR, studied by thermogravimetric analysis (Figure 1). The mass loss occurs in a rather narrow temperature range, in comparison with other pitches [23], between $350^{\circ} \mathrm{C}$ and $550^{\circ} \mathrm{C}$. The initial part of the band observed in the DTG curve (temperatures lower than $400^{\circ} \mathrm{C}$ ) can be associated mainly with the distillation of the lightest components of the mesophase. The maximum mass loss rate is around $480^{\circ} \mathrm{C}$, corresponding mainly to cracking and polymerisation reactions. Ideally, a temperature as low as $350^{\circ} \mathrm{C}$ would be desirable for the treatment, as less mass is lost. Additionally, the exudation of the precursor from the preform would be minimised if low tempeatures are used, due to a higher viscosity of the mesophase [24]. However, at 
such low temperatures pyrolysis reactions are not enough to produce significant polymerisation of the precursor. Therefore, temperatures between 400 and $475^{\circ} \mathrm{C}$ were studied.

Initially, treatments were preformed at $400{ }^{\circ} \mathrm{C}$. The results obtained are summarised in Table 1. At that temperature, $40 \mathrm{wt}$. \% of matrix was already lost, mainly due to exudation. The loss of matrix was reduced to $30 \mathrm{wt}$ \% using a presure of $0.5 \mathrm{MPa}$, the resultant sample having an open porosity of 13 vol. \%. Similar results were obtained when the pressure was raised to $0.85 \mathrm{MPa}$ and the time increased to 5 or $24 \mathrm{~h}$. However, the thermal analysis of the resultant samples indicates some differences, especially after the longest treatment. After $24 \mathrm{~h}$ at $400{ }^{\circ} \mathrm{C}$ the yield is signicantly higher (Figure 2a), i.e. no significant mass is lost thereafter, indicating a high degree of polymerisation of the precursor. This is also evidenced by the DTG curves shown in Figure 2b. After 5 h, the main changes correspond to the lightest compounds (the band of mass lost al lower temperatures), which are significantly reduced. After $24 \mathrm{~h}$, the changes are more drastic and the reduction of mass loss involves the whole range of temperatures. Furthermore, the band associated to pyrolysis reactions shifts to slightly higher temperatures ( $>500$ $\left.{ }^{\circ} \mathrm{C}\right)$.

The presence of aliphatic and methylenic groups is associated with the fluidity of the mesophase [8]; therefore, it is interesting to monitor their evolution during the thermal treatment. The infrared spectra in Figure 3 show that the intensity of the aliphatic C-H stretching bands (2800-3000 $\mathrm{cm}^{-1}$ ) assigned to methyl and methylene hydrogen decreased with the treatment due to the consumption of aliphatic hydrogen, while the 
aromatic C-H stretching bands $\left(3050 \mathrm{~cm}^{-1}\right)$ become more intense than the aliphatic ones. At the same time, the band centered at $1440 \mathrm{~cm}^{-1}$, assigned to scissoring of the methylene groups, which is initially more intense than that corresponding to aromatic $\mathrm{C}=\mathrm{C}$ stretching $\left(1600 \mathrm{~cm}^{-1}\right)$, decreases after the thermal treatment. According to the changes observed in the spectra, the aromaticity increased after the thermal treatments, from 0.39 to 0.42 after $5 \mathrm{~h}$ at $400{ }^{\circ} \mathrm{C}$, but especially after $24 \mathrm{~h}(0.49)$, as a result of the higher polymerisation degree of the mesophase promoted at these conditions.

In order to corroborate if the treatment at $400{ }^{\circ} \mathrm{C}$ for $24 \mathrm{~h}$ is in fact effective, the treated composite was then carbonised up to $1000{ }^{\circ} \mathrm{C}$. In this second stage, 14 wt. $\%$ of the matrix remaining was lost, with a total loss of mesophase in the whole process of $38 \mathrm{wt}$. $\%$ (Table 2). The porosity of the resultant composite is 23 vol. \%.

Further studies were performed increasing the treatment temperature to 450 and $475{ }^{\circ} \mathrm{C}$. After $5 \mathrm{~h}$ at $450{ }^{\circ} \mathrm{C}$, the mass lost is $22 \%$ (Table 2), a lower value than that obtained for the same period at $400{ }^{\circ} \mathrm{C}$. This is due to the higher fluidity of the mesophase at $400{ }^{\circ} \mathrm{C}$, as at $450^{\circ} \mathrm{C}$ some polymerisation reactions are already occurring. In fact, the carbon yield obtained by thermogravimetric analysis (Figure 3) is higher after the treatment at $450^{\circ} \mathrm{C}$. The DTG curves also showed a significant decrease of the bands assigned both to distillation of light compounds and pyrolysis reactions. After carbonisation, and additional 48 wt. \% was lost, resulting in a total mass loss of $60 \%$ in the whole process, a similar value to that obtained after direct carbonisation of the material (Table 1). Accordingly, the porosity in the resultant material rose to 27 vol. \%. Increasing the duration of the treatment to $10 \mathrm{~h}$, caused a significant reduction of the mass lost during 
the carbonisation stage (25\%), with an overall mass loss of $44 \%$ and a final porosity of 25 vol. \%. This was due to the higher polymerisation degree of the mesophase after this treatment, as corroborated by the thermogravimetric analysis and the aromaticity index, which increased to 0.47 (Table 3).

At $475{ }^{\circ} \mathrm{C}$ polymerisation reactions become more significant. After $5 \mathrm{~h}$ at this temperature, the mesophase is highly polymerised, as indicated by the high yield on carbonisation obtained by TG analysis (Figure 3). The DTG curve only shows a rather small band at around $500^{\circ} \mathrm{C}$. The aromaticity increased very significantly after this treatment (0.54). As a result, only a 17 wt. \% is lost in the carbonisation of the composite. Nonetheless, the mass lost during the initial curing treatment was rather high (34 wt. \%), this making the overall loss of matrix to be 45 wt. \% and the final porosity 24 vol. \%.

Additionally, carbonised composites were studied by optical microscopy in order to evaluate the effect of the thermal treatment on the anisotropy of the matrix and the distribution of porosity. Different to the reduction of anisotropy observed when quinones were added to the mesophase [21], no influence of the thermal treatments on the texture of the matrix was observed. Furthermore, the porosity was uniformly distributed throughout the material, no gradients being observed.

\section{4.- Conclusions}

Thermal curing of mesophase pitch has been proven to be a suitable method for the development of CC composites. A high degree of polymerisation of mesophase 
components was achieved with the treatments carried out at $400^{\circ} \mathrm{C}$ for $24 \mathrm{~h}$ and at $475^{\circ} \mathrm{C}$ for $5 \mathrm{~h}$, resulting in a significant reduction of the swelling and exudation of the precursor from the composite material. The materials obtained by thermal curing have similar porosity values to those obtained by oxidative stabilisation. Furthermore, there are some advantages of the method proposed, as it can be applied to materials of any thickness and avoids gradients in the properties of the composites (porosity, texture, oxygen content), which are main disadvantages of oxidative stabilisation.

Acknowledgements.- This work has been performed within the framework of the Integrated European Project “ExtreMat” (contract NMP-CT-2004-500253) with financial support by the European Community and the Spanish Education Ministry (Programa Nacional de Cooperación Internacional de Ciencia y Tecnología, Acciones Complementarias, MAT2004-22787-E). The authors would like to thank SGL Carbon Group for supplying the carbon fibre preforms. 


\section{References}

1.- $\quad$ E. Fitzer, The future of carbon-carbon composites, Carbon, 25 (1987) 163-190.

2.- $\quad$ G. Savage, Carbon-carbon composites, Chapman and Hall, London, 1993.

3.- $\quad$ A. Betram, K. Beasley, W. De la Torre, An overview of navy composite developments for thermal management, Naval Engineers J. (1992) 276-285.

4.- D.A. Bowers, J.W. Davis, R.B. Dinwiddie, Development of 1-D carbon composites for plasma-facing components, J. Nuclear Materials 212-215 (1994) 1163-1167.

5.- E. Fitzer, L.M. Manocha, Carbon Reinforcements and Carbon/Carbon Composites, Springer-Vrelag, Berlin, 1998.

6.- J.L. White, P.M. Sheaffer, Pitch-based processing of carbon-carbon composites, Carbon 27 (1989) 697-707.

7.- M. Granda, J.W. Patrick, A. Walker, E. Casal, J. Bermejo, R. Menéndez, Densification of unidirectional C/C composites by melted pitch impregnation, Carbon 36 (1998) 943-952.

8.- $\quad$ I. Mochida, Y. Korai, C-H. Ku, F. Watanabe, Y. Sakai, Chemistry of synthesis, structure, preparation and application of aromatic-derived mesophase pitch, Carbon 38 (2000) 305-328.

9.- $\quad$ K. Crist, K.J. Huttinger, Carbon-carbon-reinforced carbon composites fabricated with mesophase pitch, Carbon 31 (1993) 731-750.

10.- J.L. White, M.K. Gopalakrishnan, B. Fathollahi, A processing window for injection of mesophase pitch into a fiber preform, Carbon 32 (1994) 301-310. 
11.- $\quad$ B. Fathollahi, P.C. Chau, J.L. White, Injection and stabilization of mesophase pitch in the fabrication of carbon-carbon composites: Part II. Stabilization process, Carbon 43 (2005) 135-141.

12.- $\quad$ D.D. Edie, Pitch and mesophase fibres, in J.L. Figueiredo, C.A. Bernardo, RTK Baker, KJ Huttinger (Eds.), Carbon fibres, filaments and composites, Kluwer Academic, Boston, 1990, p. 43-72.

13.- F. Fanjul, M. Ganda, R. Santamaría, R. Menéndez, On the chemistry of the oxidative stabilization and carbonization of carbonaceous mesophase, Fuel 81, 2002, 2061-2070.

14.- J.G. Lavin, Chemical reactions in the stabilization of mesophase pitch-based carbon fiber, Carbon 30, 1992, 351-357.

15.- J. Drbohlav, W.T.K. Stevenson, The oxidative stabilization and carbonization of a synthetic mesophase pitch, part I: The oxidative stabilisation process, Carbon 33, 1995, 693-711.

16.- T. Matsumoto, I. Mochida, Oxygen distribution in oxidatively stabilized mesophase pitch fiber, Carbon 31, 1993, 143-147.

17.- $\quad$ L.S. Singer, S. Mitchell, Diffusion of oxygen into pitch, Carbon 35, 1997, 599604.

18.- $\quad$ Y.G. Lu, D. Wu, Q.F. Zha, L. Liu, Skin-core structure in mesophase pitch-based carbon fibres: causes and prevention, Carbon 36, 1998, 1719-1724.

19.- $\quad$ C. Blanco, S. Lu, S.P. Appleyard, B. Rand, The stabilisation of carbon fibres studied by micro-thermal analysis, Carbon 41, 2003, 165-171.

20.- B. Fathollahi, B. Jones, P.C. Chau, J.L. White, Injection and stabilization of mesophase pitch in the fabrication of carbon-carbon composites. Part III: 
Mesophase stabilization at low temperatures and elevated oxidation pressures, Carbon 43, 2005, 143-151.

21.- M. Dumont, M.A. Dourges, X. Bourrat, R. Pailler, R. Naslain, O. Babot, M. Birot, J.P. Pillot, Carbonization behaviour of modified synthetic mesophase pitches, Carbon 43, 2005, 2277-2284.

22.- M.D. Guillén, M.J. Iglesias, A. Domínguez, C.G. Blanco, Semiquantitative FTIR analysis of a coal tar pitch and its extracts and residues in several organic solvents, Energy and Fuels, 6, 1992, 518-525.

23.- J. Bermejo, M. Granda, R. Menéndez, J.M.D. Tascón, Comparative analysis of pitches b extrography and thermal analysis techniques, Carbon, 32, 1994, 10011010.

24.- P.M. Khandare, J.W. Zondlo, P.B. Stansberry, A. H. Stiller, Rheological investigations of pitch material. Part II: viscosity measurement of A240 and ARA-24 pitches using a high-temperature high-pressure rheometer, Carbon 38, 2000, 889-897. 


\section{Figure captions}

Figure 1.- a) TG and b) DTG curves of matrix precursors.

Figure 2.- a) TG and b) DTG curves of matrix precursors.

Figure 3.- Infrared spectra of matrix precursors. 
Table 1.- Matrix lost and porosity obtained by thermal curing at $400^{\circ} \mathrm{C}$.

\begin{tabular}{llcc}
\hline & Treatment & Matrix lost (wt. \%) & P (vol. \%) \\
\hline T-1000 & Direct carbonization & 59 & 27 \\
T400 & $400^{\circ} \mathrm{C}, 0 \mathrm{~h}$ & 40 & 17 \\
T400-0 & $400^{\circ} \mathrm{C}, 0 \mathrm{~h}, 0.5 \mathrm{MPa}$ & 30 & 13 \\
T400-5 & $400^{\circ} \mathrm{C}, 5 \mathrm{~h}, 0.85 \mathrm{MPa}$ & 27 & 13 \\
T400-24 & $400^{\circ} \mathrm{C}, 24 \mathrm{~h}, 0.85 \mathrm{MPa}$ & 28 & 13 \\
\hline
\end{tabular}

$\mathrm{P}$, open porosity 
Table 2.- Matrix lost and porosity of materials cured at different conditions.

\begin{tabular}{|c|c|c|c|c|c|}
\hline & Treatment & $\begin{array}{l}\text { Matrix lost in } \\
\text { thermal curing } \\
\text { (wt. \%) }\end{array}$ & $\begin{array}{c}\text { Matrix lost in } \\
\text { carbonization } \\
\text { (wt. \%) }\end{array}$ & $\begin{array}{c}\text { Matrix lost in } \\
\text { whole process } \\
\text { (wt. \%) }\end{array}$ & $\begin{array}{c}\mathrm{P} \\
(\text { vol. \%) }\end{array}$ \\
\hline T-1000 & Direct carbonization & - & - & 59 & 27 \\
\hline T400-24 & $\begin{array}{c}400^{\circ} \mathrm{C}, 24 \mathrm{~h}, 0.85 \mathrm{MPa} \\
\text { Carbonization }\end{array}$ & 28 & 14 & 38 & 23 \\
\hline T450-5 & $\begin{array}{c}450^{\circ} \mathrm{C}, 5 \mathrm{~h}, 0.85 \mathrm{MPa} \\
\text { Carbonization }\end{array}$ & 22 & 48 & 60 & 27 \\
\hline $\mathrm{T} 450-10$ & $\begin{array}{c}450^{\circ} \mathrm{C}, 10 \mathrm{~h}, 0.85 \mathrm{MPa} \\
\text { Carbonization }\end{array}$ & 26 & 25 & 44 & 25 \\
\hline T475-5 & $\begin{array}{c}475^{\circ} \mathrm{C} \text {, 5h, } 0.85 \mathrm{MPa} \\
\text { Carbonization }\end{array}$ & 34 & 17 & 45 & 24 \\
\hline $\begin{array}{c}\text { Oxidative } \\
\text { stabilization }\end{array}$ & $\begin{array}{c}170^{\circ} \mathrm{C}, 24 \text { h, air } \\
200^{\circ} \mathrm{C}, 12 \mathrm{~h} \text {, air } \\
\text { Carbonization }\end{array}$ & - & 40 & 40 & 22 \\
\hline
\end{tabular}


Table 3.- Aromaticity indices of matrix precursors.

\begin{tabular}{cc}
\hline Sample & Aromaticity index \\
\hline AR & 0.39 \\
T-400-5 & 0.42 \\
T-400-24 & 0.49 \\
T-450-5 & 0.44 \\
T-450-10 & 0.47 \\
T-475-5 & 0.55 \\
\hline
\end{tabular}




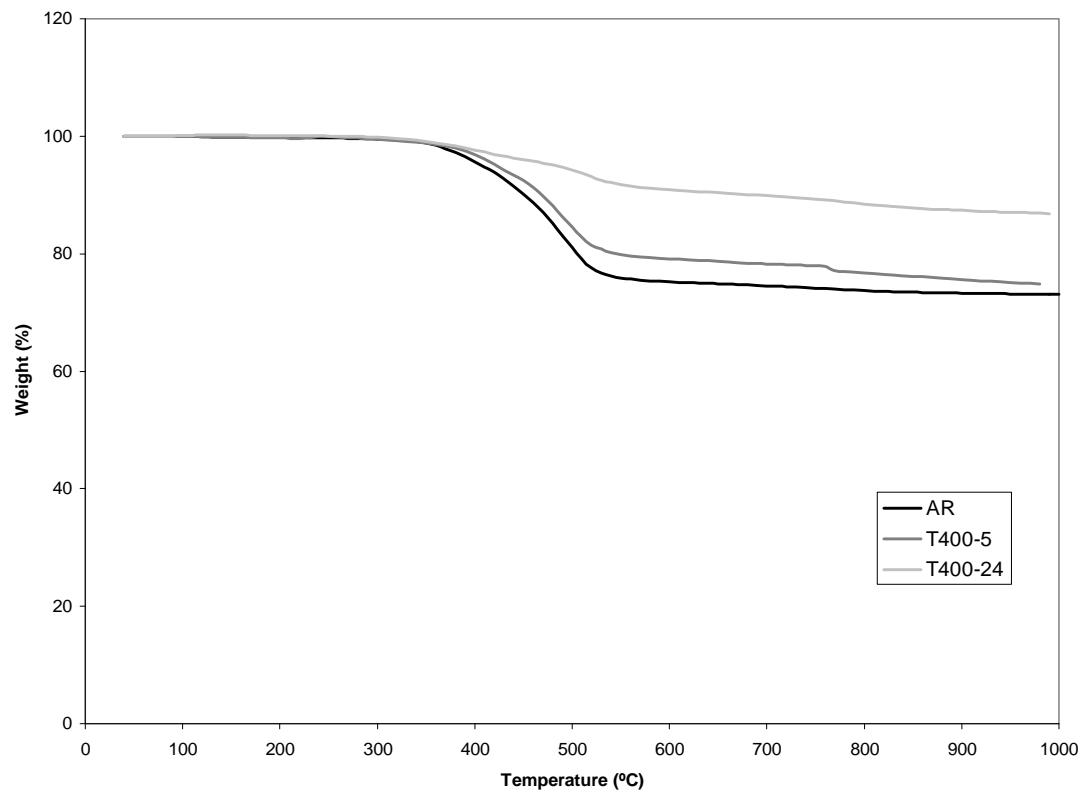

b)

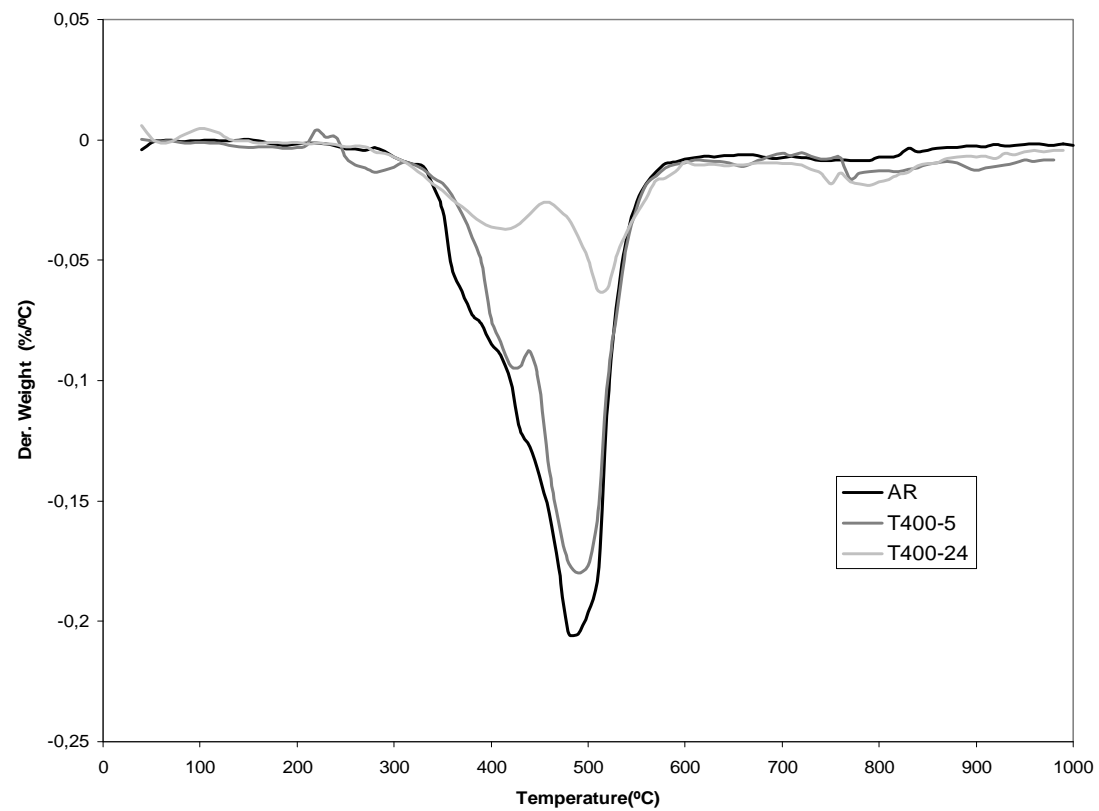

Figure 1 
a)

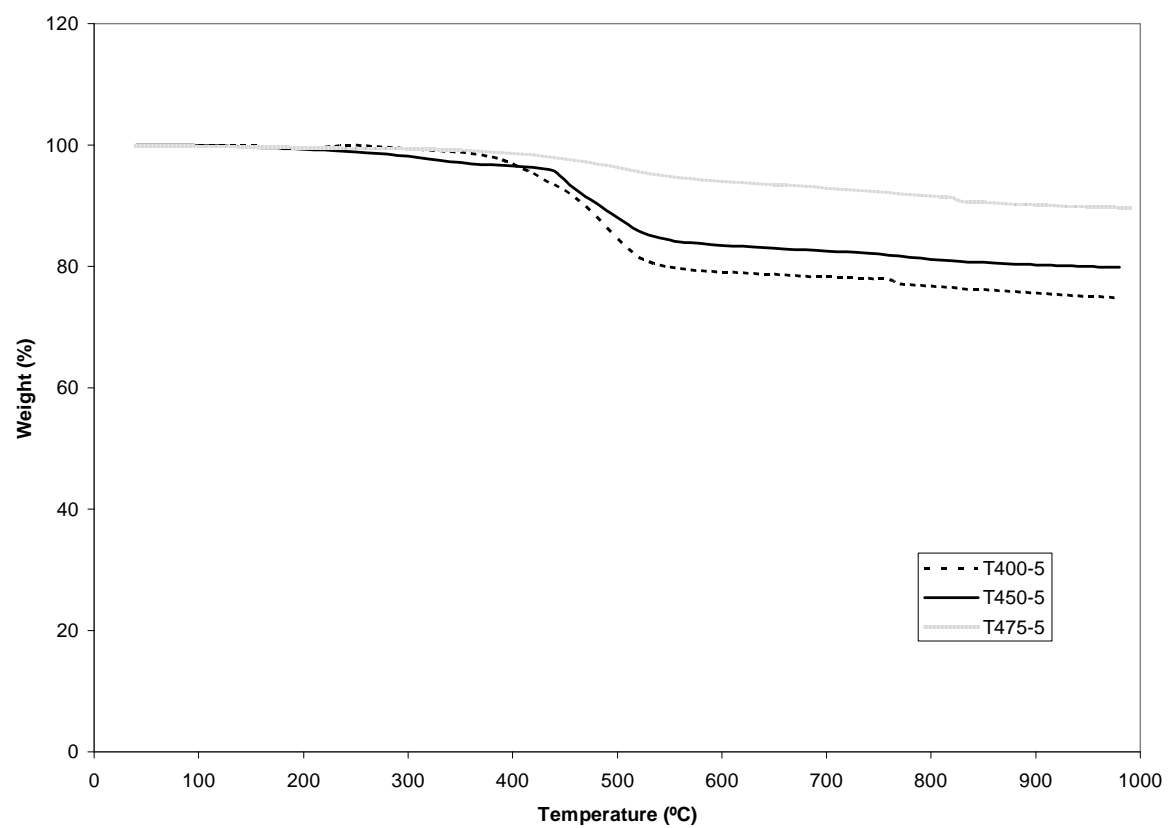

b)

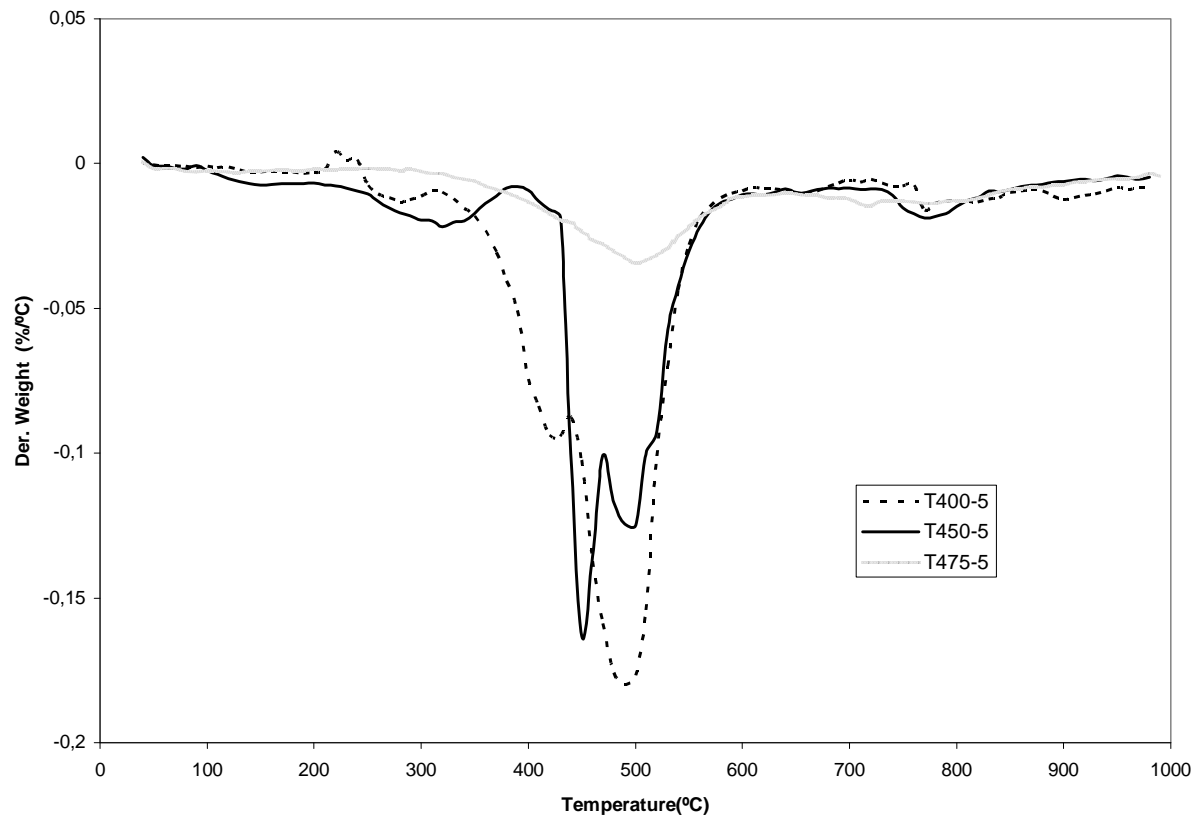

Figure 2 


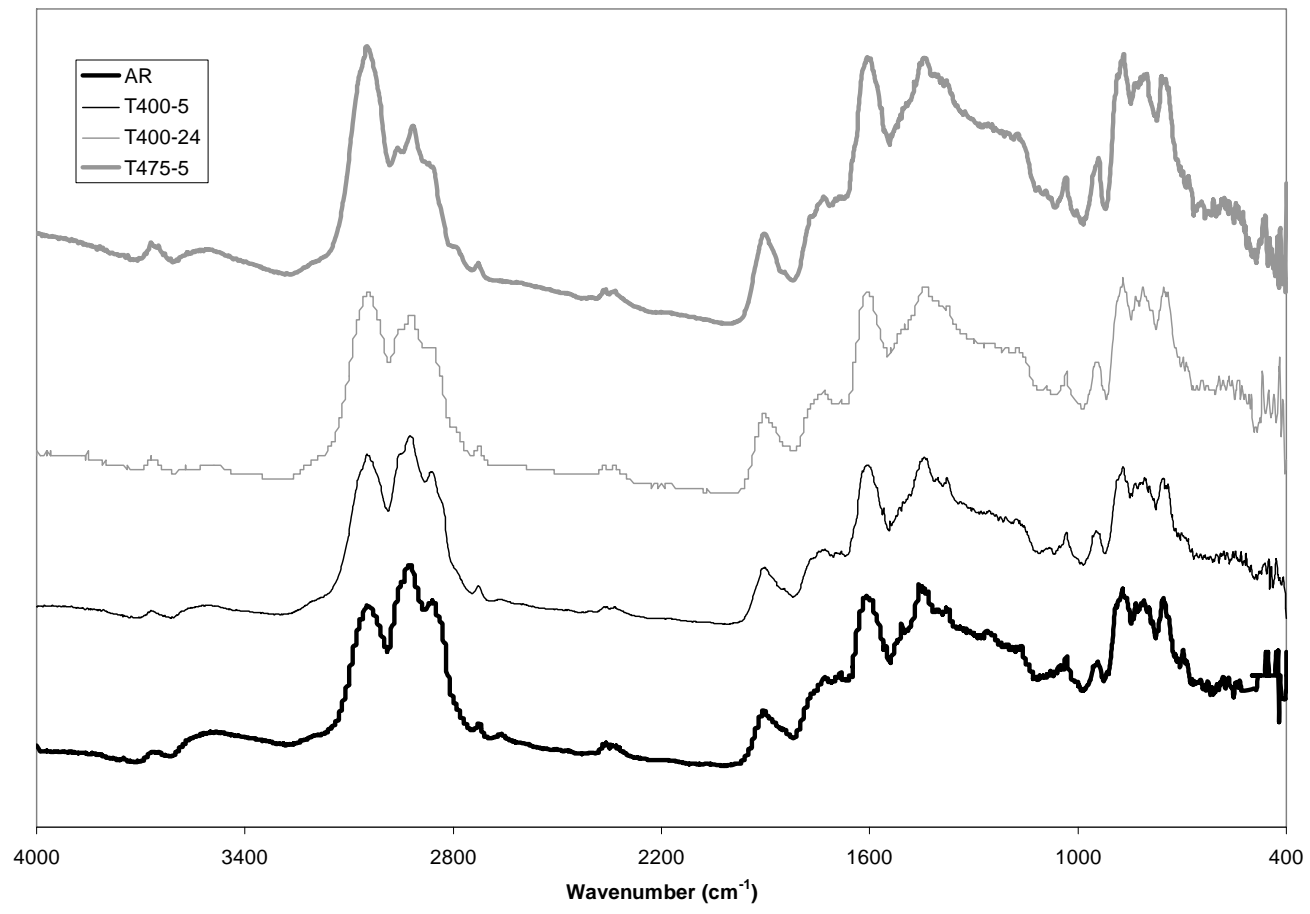

Figure 3 